Int. J. Electrochem. Sci., 15 (2020) 10922 - 10935

\title{
Discharge and Corrosion Behaviors of Mg-Li and Mg-Li-La Alloys as Anodes for Seawater Battery
}

\author{
Juxin $Y u^{1,2}$,Yanzhuo Lv ${ }^{1, *}$,Tigang Duan ${ }^{2, *}$, Fei Meng ${ }^{1}$, Qing Cheng ${ }^{1}$, Yan Xu ${ }^{4}$, Kaiwen Zhou ${ }^{1}$, \\ Lili Xue ${ }^{1}$, Zhe Leng ${ }^{3, *}$. \\ ${ }^{1}$ Key Laboratory of Superlight Material and Surface Technology of Ministry of Education, the College \\ of Material Science and Chemical Engineering, Harbin Engineering University, Harbin 150001, P.R. \\ China; \\ ${ }^{2}$ State Key Laboratory for Marine Corrosion and Protection, Luoyang Ship Material Research Institute, \\ Qingdao 266237, P.R. China; \\ ${ }^{3}$ Innovation and Application Institute, Zhejiang Ocean University, Zhoushan 316022, P.R. China; \\ ${ }^{4}$ Engineering Training Center, Harbin Engineering University, Harbin 150001, China. \\ *E-mail: lvyanzhuo@,hrbeu.edu.cn, duantigang@sunrui.net, lengzhe@,zjou.edu.cn
}

doi: $10.20964 / 2020.11 .02$

Received: 16 June 2020 / Accepted: 12 August 2020 / Published: 30 September 2020

The electrochemical performance of Mg-8Li-0.5La and Mg-8Li-1La alloy as anodes for seawater battery were investigated by electrochemical techniques. Scanning electron microscopy (SEM) was used to characterize the microstructures and the corroded surfaces of the above anodes. X-ray diffraction (XRD) was used to analyze the composition and the crystalline pattern of the discharging products. Results show that $\mathrm{Mg}-8 \mathrm{Li}-1 \mathrm{La}$ anode has the higher electrochemical activity and the better corrosion resistance. Potentiodynamic polarization shows that the corrosion potentials of $\mathrm{Mg}-8 \mathrm{Li}-1 \mathrm{La}$ alloy anode and $\mathrm{Mg}$ 8Li-0.5La alloy anode are $-1.64 \mathrm{~V}$ and $-1.67 \mathrm{~V}$ (vs. SCE), respectively, which are more active than the $\mathrm{Mg}-8 \mathrm{Li}$ alloy anode(-1.57 V vs. SCE). The current densities for anodes at the discharge voltage of -1.0 $\mathrm{V}$ increase with the following order: $\mathrm{Mg}-8 \mathrm{Li}\left(31 \mathrm{~mA} \cdot \mathrm{cm}^{-2}\right)<\mathrm{Mg}-8 \mathrm{Li}-0.5 \mathrm{La}\left(35 \mathrm{~mA} \cdot \mathrm{cm}^{-2}\right)<\mathrm{Mg}-8 \mathrm{Li}-$ $1 \mathrm{La}\left(42 \mathrm{~mA} \cdot \mathrm{cm}^{-2}\right)$. The $\mathrm{Mg}-8 \mathrm{Li}-1 \mathrm{La}$ alloy anode provides a more negative voltage than $\mathrm{Mg}-8 \mathrm{Li}-0.5 \mathrm{La}$ alloy anode and $\mathrm{Mg}-8 \mathrm{Li}$ alloy anode during the galvanostatic discharge test. Therefore, the content of La in alloys obviously affects the electrochemical performance of alloys.

Keywords: Mg-8Li-0.5La; Mg-8Li-1La; Alloy anode; Discharge behaviors; Electrochemical performance; Sodium chloride solution

\section{$\underline{\text { FULL TEXT }}$}


(C) 2020 The Authors. Published by ESG (www.electrochemsci.org). This article is an open access article distributed under the terms and conditions of the Creative Commons Attribution license (http://creativecommons.org/licenses/by/4.0/). 